Check for updates

Cite this: RSC Adv., 2019, 9, 26373

Received 25th April 2019

Accepted 7th August 2019

DOI: 10.1039/c9ra03109j

rsc.li/rsc-advances

\section{Micro-mechanical properties of a novel silicon nitride fiber reinforced silicon carbide matrix composite via in situ nano-indentation method}

\begin{abstract}
Xun Sun, Ru Jiang, Haitao Liu (D)* and Haifeng Cheng
A novel $\mathrm{Si}_{3} \mathrm{~N}_{4}$ fiber reinforced $\mathrm{SiC}$ matrix composite has been prepared and the micro-mechanical properties of the composites in situ have been explored. For the $\mathrm{Si}_{3} \mathrm{~N}_{4}$ fibers, the micro-mechanical properties in situ remained almost unchanged with the increasing fabrication temperatures. In comparison, for the PCS derived SiC matrix, higher fabrication temperature could trigger more $\beta$-SiC formations, which led to enlarging the corresponding micro-mechanical properties. The microstructure analysis of the interfacial zones in the composites revealed strong interfacial reactions existing in the composites fabricated at $\geq 800{ }^{\circ} \mathrm{C}$. Therefore, the interfacial shear strength of the composite was significantly increased from $\sim 420 \mathrm{MPa}$ to $\sim 535 \mathrm{MPa}$ with the fabrication temperature increasing from $800{ }^{\circ} \mathrm{C}$ to $1200{ }^{\circ} \mathrm{C}$, thus impeding the toughening mechanisms of the composites. After introducing BN interphase, the interfacial shear strength was significantly reduced to $\sim 140 \mathrm{MPa}$ and the flexural strength was increased from $\sim 140 \mathrm{MPa}$ to $\sim 250 \mathrm{MPa}$. The work highlights the efficiency of introducing BN interphase to weaken the interfacial interaction, thus to enhance the macro-mechanical properties.
\end{abstract}

\section{Introduction}

The silicon carbide (SiC) ceramic has excellent mechanical strength at elevated temperature, high oxidation resistance, and high thermal conductivity, etc. ${ }^{1-5}$ In addition, owing to the excellent semiconductivity and relatively stable dielectric properties at elevated temperature, $\mathrm{SiC}$ can be extended to the potential application for microwave absorption materials at high temperature. ${ }^{6,7}$ However, due to the inherent brittle failure behavior of monolithic $\mathrm{SiC}$ ceramic, it has been gradually substituted by ceramic fibers reinforced $\mathrm{SiC}$ matrix composites, like $\mathrm{C}_{\mathrm{f}} / \mathrm{SiC}, \mathrm{SiC}_{\mathrm{f}} / \mathrm{SiC}$ and $\mathrm{Si}_{3} \mathrm{~N}_{4 \mathrm{f}} / \mathrm{SiC}$ composites, which can significantly improve the toughness of monolithic $\mathrm{SiC}$ ceramic. ${ }^{8-11}$ Among these fiber reinforcements, $\mathrm{Si}_{3} \mathrm{~N}_{4}$ fiber, owing to its high oxidation resistance and superior electrical insulating property at elevated temperature, is an optimal candidate for the reinforcement of SiC matrix composites in the application for microwave absorption materials. ${ }^{12-14}$ However, to the best of our knowledge, the systematic mechanical properties of the $\mathrm{Si}_{3} \mathrm{~N}_{4 \mathrm{f}} / \mathrm{SiC}$ composites have been rarely reported in detail.

Motivated by this, the mechanical properties of the $\mathrm{Si}_{3} \mathrm{~N}_{4 \mathrm{f}} /$ $\mathrm{SiC}$ composites fabricated at different temperatures were investigated, including micro- and macro- mechanical properties. The macro-mechanical properties of ceramic fiber

College of Aerospace Science and Engineering, National University of Defense Technology, Changsha 410073, China. E-mail: htslht@163.com; Fax: +86 731 84573194; Tel: +8673184574578 reinforced ceramic matrix composites (CFRCMCs), like flexural strength and fracture toughness, can be easily obtained through the testing standards..$^{15}$ However, due to the test method limitations, the micro-mechanical properties in situ, like the Young's modulus and the fracture toughness of both fiber and matrix, the interfacial shear strength of the fiber/matrix interface, have been barely reported systematically. As is well-known, since the mechanical property of the composites in a micro scale has significant effect on the ultimate strength of the composites, it is critical to study fundamentally the micromechanical property in situ. Fortunately, benefited from the development of the instrumented micro-mechanical testing methods like nanoindentation, ${ }^{16-21}$ fiber push-in/push-out, ${ }^{22-25}$ micropillar splitting method, ${ }^{26,27}$ etc., the micro-mechanical properties in situ can be achieved. For example, the Young's modulus and hardness of the ceramic matrix and the ceramic fiber can be quantified by the nanoindentation method; the interfacial shear strength can be measured based on the fiberpush-in/push-out methods.

In addition, due to the predictably interface reactions at the fiber/matrix interface during high-temperature fabrication process $\left(\geq 800{ }^{\circ} \mathrm{C}\right)$, the $\mathrm{Si}_{3} \mathrm{~N}_{4 \mathrm{f}} / \mathrm{SiC}$ composites can be very brittle, which may lead to catastrophic failures when they are sustained complex stress states. ${ }^{28}$ By using proper interphase, the interfacial interaction in the composites can be effectively weakened, thus a typical toughening mechanism, crack deflection at interface, can be triggered. BN interphase with low dielectric constant characteristics, as a widely-used interphase material for ceramic matrix composites was introduced into the $\mathrm{Si}_{3} \mathrm{~N}_{4 \mathrm{f}} /$ 
SiC composites to weaken the interfacial bonding and thus develop the toughness of the composites. ${ }^{29,30}$ Consequently, first of all this work contributed to explore the in situ micromechanical properties of the $\mathrm{Si}_{3} \mathrm{~N}_{4 \mathrm{f}} / \mathrm{SiC}$ composites without and with $\mathrm{BN}$ interphase in detail. Moreover, the macromechanical properties of the composites were measured.

\section{Experimental}

\subsection{Materials preparation}

A KD-SN type $\mathrm{Si}_{3} \mathrm{~N}_{4}$ fiber preform (provided by our own laboratory) was chosen as reinforcements of the $\mathrm{Si}_{3} \mathrm{~N}_{4 \mathrm{f}} / \mathrm{SiC}$ composites. The correlated microstructure changes have been reported in our previous report. The $\mathrm{Si}_{3} \mathrm{~N}_{4 \mathrm{f}} / \mathrm{SiC}$ composite was fabricated by conventional precursor infiltration and pyrolysis (PIP) process, using polycarbosilane (PCS, from our own laboratory) as matrix precursor. Three $\mathrm{Si}_{3} \mathrm{~N}_{4 \mathrm{f}} / \mathrm{SiC}$ composites were fabricated finally, labeled $\mathrm{Si}_{3} \mathrm{~N}_{4 \mathrm{f}} / \mathrm{SiC}-800{ }^{\circ} \mathrm{C}, \mathrm{Si}_{3} \mathrm{~N}_{4 \mathrm{f}} / \mathrm{SiC}-1000{ }^{\circ} \mathrm{C}, \mathrm{Si}_{3} \mathrm{~N}_{4 \mathrm{f}} / \mathrm{SiC}-1200{ }^{\circ} \mathrm{C}$, representing $\mathrm{Si}_{3} \mathrm{~N}_{4 \mathrm{f}} / \mathrm{SiC}$ fabricated at $800{ }^{\circ} \mathrm{C}, 1000{ }^{\circ} \mathrm{C}$ and $1200{ }^{\circ} \mathrm{C}$ respectively. More than 15 cycles were performed to obtain a relatively dense microstructure of matrix. This was signified by $<1 \%$ weight increase of the composite during the subsequent PIP cycles. The BN coatings were prepared on the fiber bundles by chemical vapor deposition (CVD) method prior to the matrix fabrication. Borazine was used as precursors for the BN deposition. The deposition was performed at low pressure $(1 \mathrm{kPa})$ and moderate temperature $\left(1100^{\circ} \mathrm{C}\right)$.

\subsection{Materials microstructure characterization}

The morphology of these composites were observed by scanning electron microscopy (SEM, Hitachi FEG S4800). The phase composition of these composites was observed by by X-ray diffraction (XRD) analysis using a D8 ADVANCE diffractometer (Bruker, Germany). Microstructures of the SiC matrix and the interfacial microstructures of the composites were performed using an FEI Tecnai F20 transmission electron microscope operating at $200 \mathrm{kV}$. The TEM of the interfacial microstructures specimens were prepared by a milling-andlifting out process inside a focused ion beam (FIB) system (FEI Helios 600i).

\subsection{Mechanical property characterization}

Instrumented nanoindentation test was conducted on the individual $\mathrm{Si}_{3} \mathrm{~N}_{4}$ fiber and $\mathrm{SiC}$ matrix on a finely polished crosssection of the $\mathrm{Si}_{3} \mathrm{~N}_{4 \mathrm{f}} / \mathrm{SiC}$ composite, employing a Berkovich diamond indenter (Keysight G200) to measure the Young's modulus and the hardness of each component versus the indenter depth using the continuous stiffness measurement (CSM) method..$^{31}$ The load rate was $30 \mathrm{mN} \mathrm{s}^{-1}$. Similarly, the in situ fracture toughness of the SiC matrix on the cross-section of the $\mathrm{Si}_{3} \mathrm{~N}_{4 \mathrm{f}} / \mathrm{SiC}$ composite was measured using the same diamond indenter. The only difference was that the load in the fracture toughness test was much higher than in the common nanoindentation test. The in situ fracture toughness of the $\mathrm{Si}_{3} \mathrm{~N}_{4}$ fiber was measured using micropillar splitting test which has been reported in our previous study. ${ }^{32}$
The interfacial shear strength of the composites was quantified by instrumented fiber push-in tests inside the Keysight G200 nano-mechanical testing system. A $5 \mu \mathrm{m}$ flat diamond punch was used to apply the external force, which was strictly parallel to the interface. The displacement rate was $30 \mathrm{~nm} \mathrm{~s}^{-1}$ and the maximum depth $2 \mu \mathrm{m}$. At least 10 fibers were selected to perform the tests, until reproducible results were obtained. The flexural strength of the $\mathrm{Si}_{3} \mathrm{~N}_{4 \mathrm{f}} / \mathrm{SiC}$ and the $\mathrm{Si}_{3} \mathrm{~N}_{4 \mathrm{f}} / \mathrm{BN} / \mathrm{SiC}$ composites was obtained by the three-point bend (TPB) techniques inside an Instron 1342 Universal Testing Machine, according to ASTM D790.

\section{Results and discussions}

\subsection{Microstructure analysis of the $\mathrm{Si}_{3} \mathrm{~N}_{4 \mathrm{f}} / \mathrm{SiC}$ composite}

The cross-sectional morphology of the $\mathrm{Si}_{3} \mathrm{~N}_{4 \mathrm{f}} / \mathrm{SiC}-800{ }^{\circ} \mathrm{C}, \mathrm{Si}_{3} \mathrm{~N}_{4 \mathrm{f}} /$ SiC-1000 ${ }^{\circ} \mathrm{C}, \mathrm{Si}_{3} \mathrm{~N}_{4 \mathrm{f}} / \mathrm{SiC}-1200{ }^{\circ} \mathrm{C}$ was shown in Fig. 1. As expected, the fibers with a diameter of $\sim 12 \mu \mathrm{m}$ was compactly bridged by dense SiC matrix, with only a few pores observed in the selected region.

The phase composition of the composites was investigated by XRD analysis, as shown in Fig. 2. It was obviously found that there was mainly composed of SiC phase in the XRD patterns due to the better crystallinity of the $\mathrm{SiC}$ matrix than the $\mathrm{Si}_{3} \mathrm{~N}_{4}$ fiber in the same fabrication temperature. In our previous study, the $\mathrm{Si}_{3} \mathrm{~N}_{4}$ fiber can still remain amorphous until the temperature was increased up to $1200{ }^{\circ} \mathrm{C}$. With the rise of temperature, the main diffraction peaks at $36^{\circ}$ and $60^{\circ}$ respectively corresponding to (111) and (220) planes of $\beta$-SiC became increasingly apparent, which indicated that for the PCS derived SiC matrix, higher temperature could trigger more $\beta$-SiC formations. The pyrolytic process of the PCS could be explained

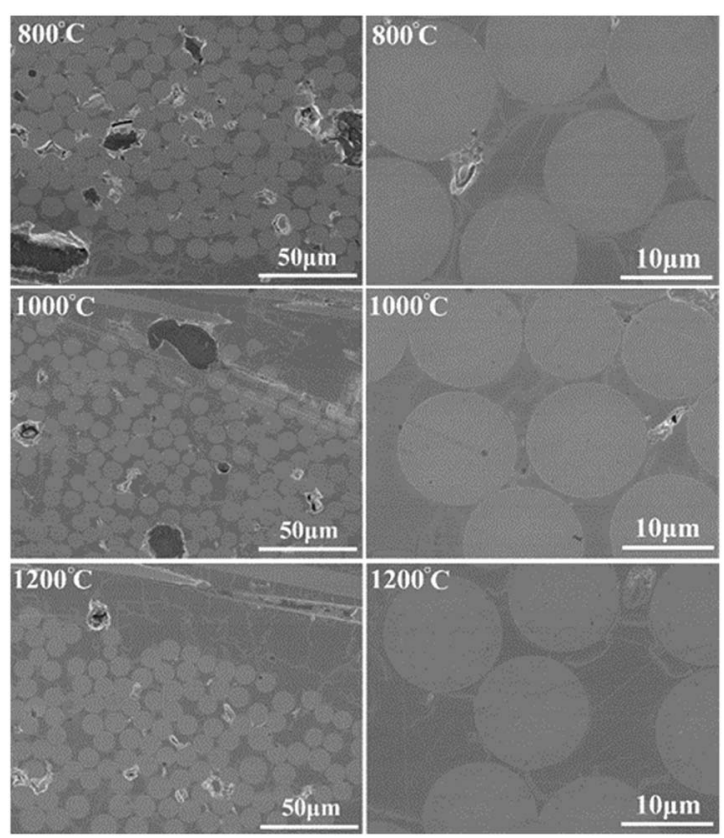

Fig. 1 Cross-sectional images of $\mathrm{Si}_{3} \mathrm{~N}_{4 f} / \mathrm{SiC}$ composites fabricated at different temperatures. 


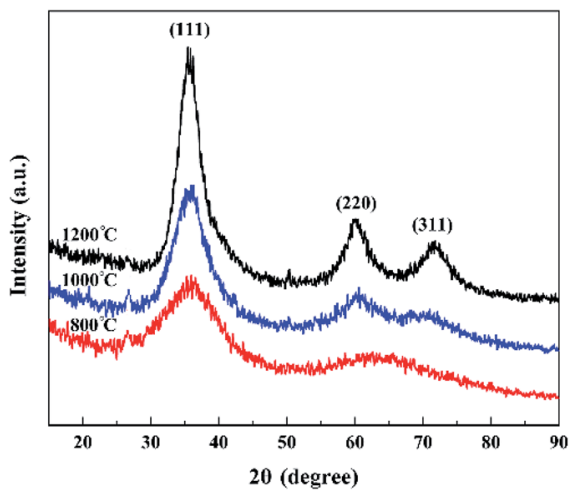

Fig. 2 XRD patterns of $\mathrm{Si}_{3} \mathrm{~N}_{4 f} / \mathrm{SiC}$ composites fabricated at different temperatures.

as below: when the fabrication temperature was at $800{ }^{\circ} \mathrm{C}$, the pyrolysis product of PCS remaining amorphous was the homogeneous inorganic substance, including amorphous SiC and $\mathrm{Si}-\mathrm{O}-\mathrm{C}$ structure. With the fabrication temperature up to $1000{ }^{\circ} \mathrm{C}$, the decomposition of $\mathrm{Si}-\mathrm{O}-\mathrm{C}$ structure and the crystallization of the amorphous SiC resulted in the formation of the $\mathrm{SiC}$ crystallite. It was proved by the TEM analysis of the SiC matrix as shown in Fig. 3 . The high resolution and selected area electronic diffraction (SAED) analysis revealed the amorphous
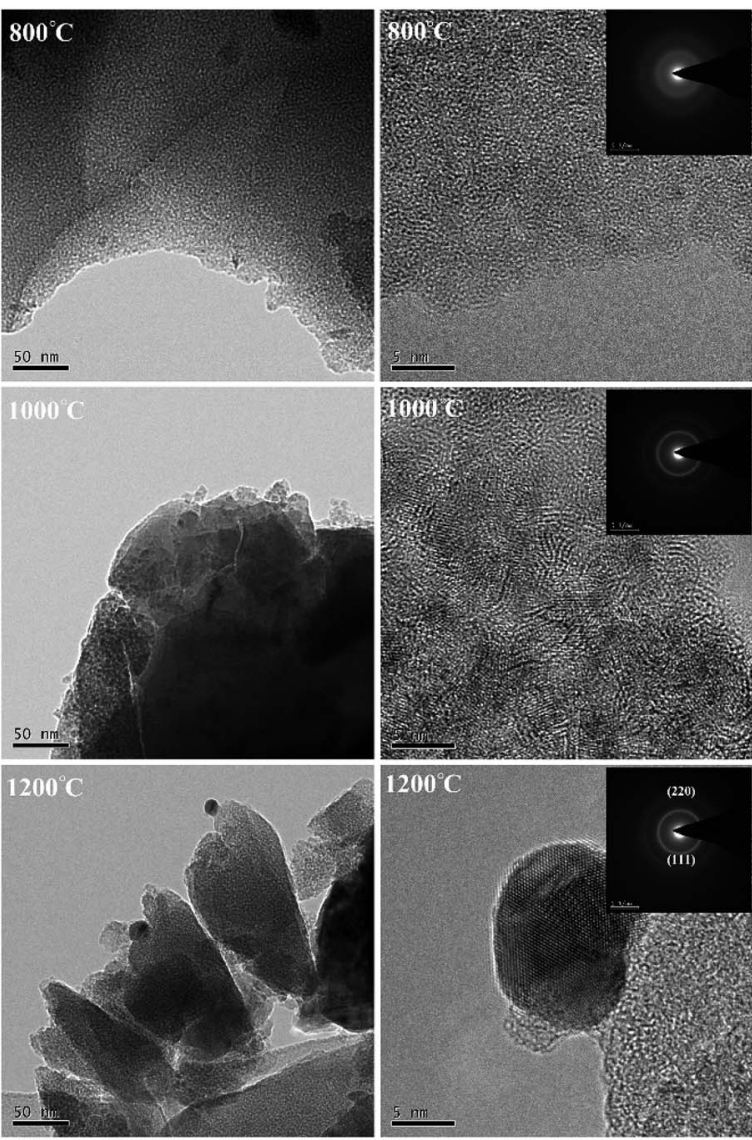

Fig. 3 TEM analysis of SiC matrix fabricated at different temperatures. nature of the $\mathrm{SiC}$ matrix at $800{ }^{\circ} \mathrm{C}$. When the fabrication temperature was increased up to $1000{ }^{\circ} \mathrm{C}$ or above, the SAED ring became more and more distinct and further addressed the stronger diffractions of (111) and (220) crystalline planes of SiC matrix at higher fabrication temperatures.

The cross-sectional TEM images of interfacial zones in the $\mathrm{Si}_{3} \mathrm{~N}_{4 \mathrm{f}} / \mathrm{SiC}-800{ }^{\circ} \mathrm{C}$ composite were shown in Fig. 4 . As expected, the $\mathrm{Si}_{3} \mathrm{~N}_{4}$ fiber was amorphous, even after the harsh PIP process. It was obviously observed an interphase with the thickness of $\sim 20 \mathrm{~nm}$ was formed in the fiber/matrix interface. The EDS analysis in Fig. 4(c) revealed the interphase was mainly composed of Si and O elements, which indicated a formation of $\mathrm{SiO}_{2}$ phase at the fiber/matrix interface. This thin interphase was mainly resulted from the potential interfacial reactions between the two phases at $\geq 800{ }^{\circ} \mathrm{C}$. In our previous work, the oxygen group of the $\mathrm{Si}_{3} \mathrm{~N}_{4}$ fiber was mainly distributed on the fiber surface. ${ }^{12}$ Therefore, this $\mathrm{SiO}_{2}$ interphase was possibly a reaction product of the oxygen group of the $\mathrm{Si}_{3} \mathrm{~N}_{4}$ fiber with the -Si-O-Si- group of the PCS at the fabrication temperature $\geq$ $800{ }^{\circ} \mathrm{C}^{33,34}$ The potential interfacial reactions are as follows:

$$
\begin{gathered}
\equiv \mathrm{Si}-\mathrm{H}+\mathrm{O} \rightarrow \equiv \mathrm{Si}-\mathrm{OH} \\
2 \equiv \mathrm{Si}-\mathrm{OH} \rightarrow \mathrm{Si}-\mathrm{O}-\mathrm{O}-\mathrm{Si} \equiv+\mathrm{H}_{2} \mathrm{O}
\end{gathered}
$$

Hence, the fiber/matrix interface in the $\mathrm{Si}_{3} \mathrm{~N}_{4 \mathrm{f}} / \mathrm{SiC}$ composite was reaction-controlled at the fabrication temperature $\geq$ $800{ }^{\circ} \mathrm{C}$, which would result in strong interfacial reactions.

The strong interfacial reaction in the $\mathrm{Si}_{3} \mathrm{~N}_{4 \mathrm{f}} / \mathrm{SiC}$ composite can be effectively eliminated by depositing BN interphase on the
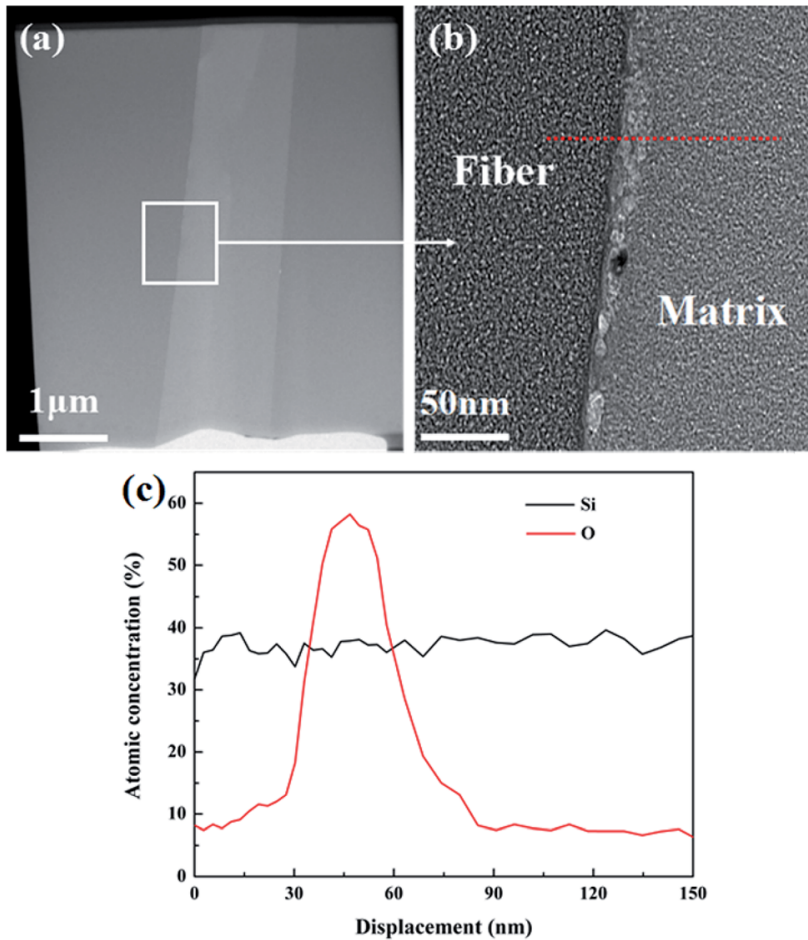

Fig. 4 (a and b) Interfacial zone analysis of the $\mathrm{Si}_{3} \mathrm{~N}_{4 f} / \mathrm{SiC}-800{ }^{\circ} \mathrm{C}$ composite; (c) EDS analysis of the red dashed line in (b). 
fiber surface via chemical vapor deposition (CVD). The crosssectional morphology of the $\mathrm{Si}_{3} \mathrm{~N}_{4 \mathrm{f}} / \mathrm{SiC}-800{ }^{\circ} \mathrm{C}$ composite with BN interphase was shown in Fig. 5. The interphase with $\sim 400 \mathrm{~nm}$ was uniformly deposited around the fibers.

The cross-sectional TEM images of interfacial zones in $\mathrm{Si}_{3} \mathrm{~N}_{4 \mathrm{f}} / \mathrm{SiC}-800{ }^{\circ} \mathrm{C}$ composite with BN interphase were shown in Fig. 6. The high resolution TEM (HR-TEM) and selected area electronic diffraction (SAED) of the BN interphase in Fig. 6(d) indicated the interphase was in graphite-like structure with a short range of crystallinity being on atomic scale, implying the favorable cracks deflection when matrix cracks spread to the interphase. It was obviously found the fiber/interphase/matrix interfaces were chemical sharp, indicating the potential interfacial reactions that occurred in the $\mathrm{Si}_{3} \mathrm{~N}_{4 \mathrm{f}} / \mathrm{SiC}$ composite can be effectively prevented by introducing BN interphase.

\subsection{Young's modulus and hardness of the fiber and matrix}

The Young's modulus and hardness of the fiber and matrix were measured by nano-indentation instrument based on Oliver \& Pharr method. The fabrication-temperature dependent Young's modulus and hardness of the fiber and matrix in the $\mathrm{Si}_{3} \mathrm{~N}_{4 \mathrm{f}} / \mathrm{SiC}$ composites versus indentation depth were showed in Fig. 7. The data fluctuation in the initial displacement of $\sim 50 \mathrm{~nm}$ was resulted from the contact between the sample and the indenter. Up to a depth of 50-300 nm, the Young's modulus and hardness of both constituents showed independent on the indentation depth. The measured Young's modulus and hardness were listed in Table 1. The Young's modulus and the hardness of the fiber at 800-1200 ${ }^{\circ} \mathrm{C}$ were leveled $\sim 165 \mathrm{GPa}$ and $\sim 16 \mathrm{GPa}$, respectively, which were independent of the fabrication temperature. It was mainly a consequence of the structure stability of the $\mathrm{Si}_{3} \mathrm{~N}_{4}$ fiber at this temperature interval. In comparison, the increasing fabrication temperature from $800{ }^{\circ} \mathrm{C}$ to $1200{ }^{\circ} \mathrm{C}$ resulted in the significant enhancements of the Young's modulus from $\sim 143 \mathrm{GPa}$ to $\sim 213 \mathrm{GPa}$ and the hardness from $\sim 14 \mathrm{GPa}$ to $\sim 21$ GPa for the SiC matrix, indicating the strong effect of the composite fabrication temperature on the mechanical property of the SiC matrix. This was expected since the matrix was expected to have a higher ratio of the $\beta$-SiC than the $\alpha$-SiC at higher fabrication temperatures. Since the Young's modulus of $\beta$-SiC is much higher than that of the $\alpha$-SiC, the stiffer and stronger SiC matrix obtained at higher temperatures should be mainly attributed to the higher content $\beta$-SiC formations. ${ }^{35,36}$
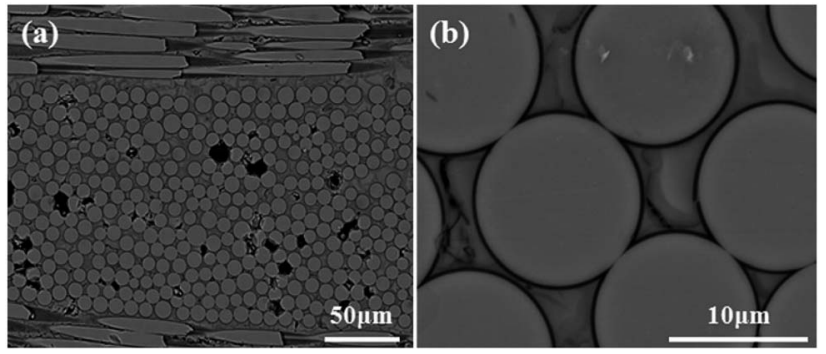

Fig. 5 (a) Cross-sectional image of the $\mathrm{Si}_{3} \mathrm{~N}_{4 f} / \mathrm{SiC}-800{ }^{\circ} \mathrm{C}$ composite with $\mathrm{BN}$ interphase; (b) partial enlarged drawing of the cross-sectional image.

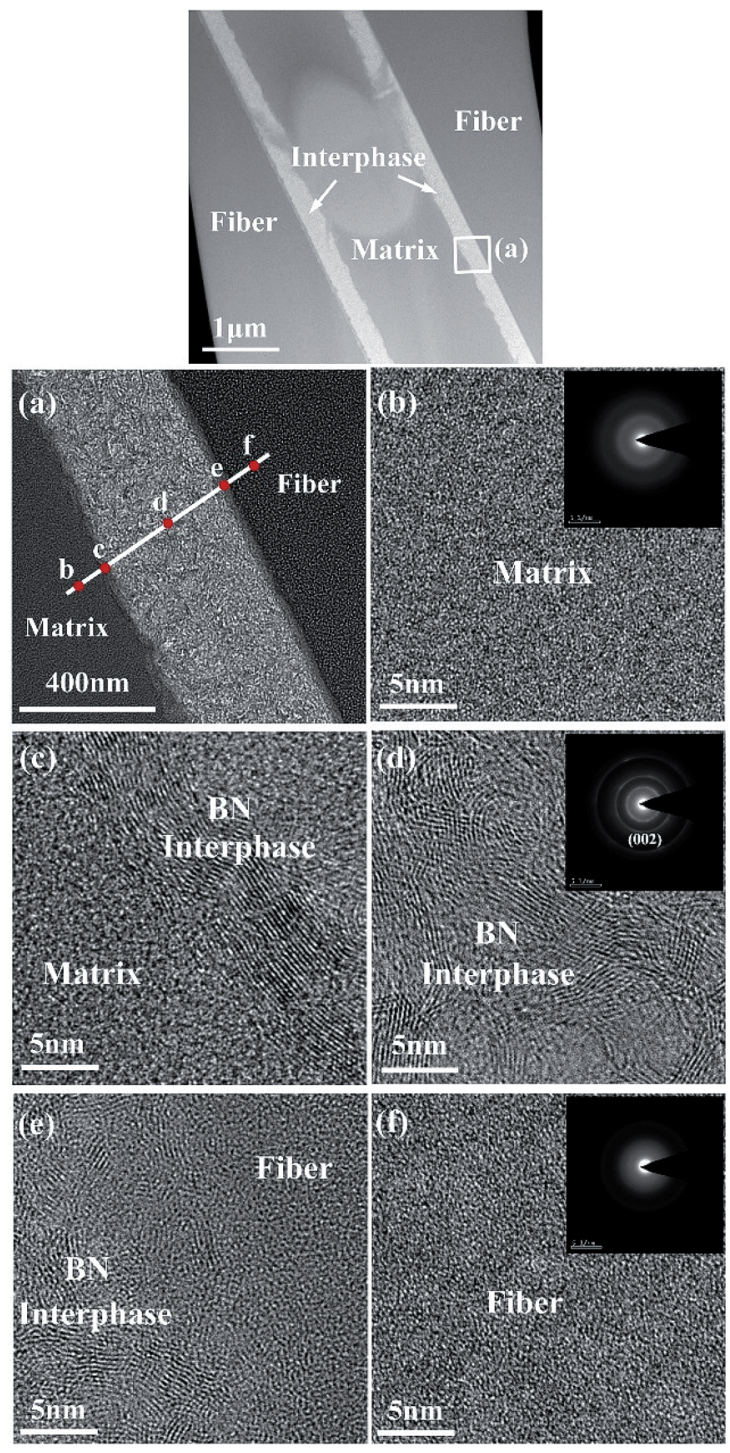

Fig. 6 Interfacial zone image of the $\mathrm{Si}_{3} \mathrm{~N}_{4 \mathrm{f}} / \mathrm{SiC}-800^{\circ} \mathrm{C}$ composite with $\mathrm{BN}$ interphase: (a) partial enlarged drawing of the interfacial zone image; (b) HR-TEM and SAED of the SiC matrix; (c) HR-TEM of the matrix/interphase interface; (d) HR-TEM and SAED of the BN interphase; (e) HR-TEM of the interphase/fiber interface; (f) HR-TEM and SAED of the $\mathrm{Si}_{3} \mathrm{~N}_{4}$ fiber.

\subsection{Fracture toughness of the fiber and matrix}

The fracture toughness of the SiC matrix was measured by nanoindentation with a cube-corned diamond indenter to generate indents inside the SiC matrix fabricated at different temperatures. The specific experimental process was similar with the above conventional nano-indentation tests. This indentation test needed higher load to generate cracks from the center of the indents. The fracture toughness of the matrix was estimated from the nano-indentation method and typical LEM (LawnEvans-Marshall) eqn (1). ${ }^{37}$

$$
K_{\mathrm{IC}}=\alpha \sqrt{\frac{E}{H}}\left(\frac{P_{\max }}{c^{2 / 3}}\right)
$$



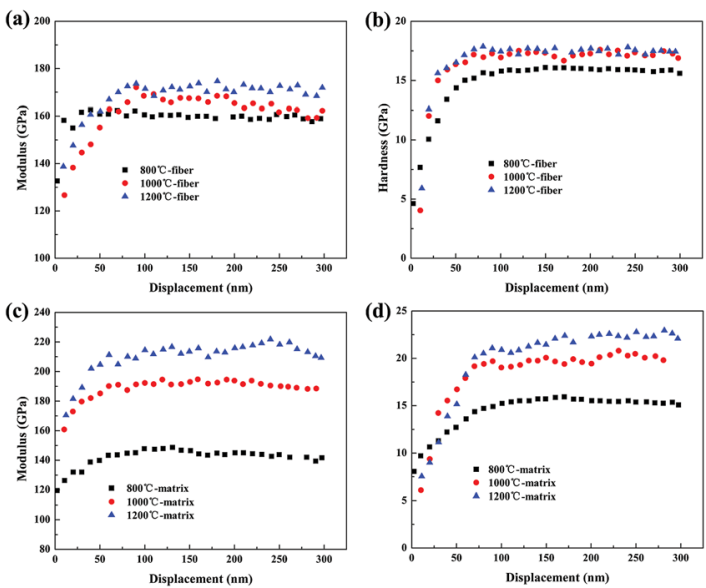

Fig. 7 ( $a$ and b) Young's modulus and hardness of the fiber at different temperatures; (c and d) Young's modulus and hardness of the matrix at different temperatures.

Table 1 Young's modulus and hardness of the fiber and matrix

\begin{tabular}{llllll}
\hline & \multicolumn{2}{l}{ Young's modulus (GPa) } & & \multicolumn{2}{l}{ Hardness $(\mathrm{GPa})$} \\
\cline { 2 - 3 }$T\left({ }^{\circ} \mathrm{C}\right)$ & Fiber & Matrix & & Fiber & Matrix \\
\hline 800 & $162.1 \pm 8.6$ & $143.7 \pm 7.9$ & & $15.3 \pm 2.2$ & $14.1 \pm 1.6$ \\
1000 & $165.2 \pm 8.2$ & $191.2 \pm 8.6$ & & $16.7 \pm 1.3$ & $19.6 \pm 2.9$ \\
1200 & $171.5 \pm 9.7$ & $213.9 \pm 8.9$ & & $17.3 \pm 1.5$ & $21.7 \pm 1.1$
\end{tabular}

where $E$ was the elastic modulus, $H$ was the hardness, $P_{\max }$ was the maximum load applied to the matrix, $c$ was the length of the crack path from the center of the indents and $\alpha$ was an empirically determined calibration constant, taken as 0.016 .

This test set $\sim 600 \mathrm{mN}$ as the maximum load on the matrix in order to generate distinct cracks. The corresponding loaddisplacement curves and indentation morphology of the SiC matrix after indentation tests were shown in Fig. 8. It was clearly observed that the cracks were formed from the center of the indents. With the temperature increased from $800{ }^{\circ} \mathrm{C}$ to $1200{ }^{\circ} \mathrm{C}$, the crack length turned into short. The estimated fracture toughness values are summarised in Table 2 , which increased from $\sim 1.03 \mathrm{MPa} \mathrm{m}^{1 / 2}$ at $800{ }^{\circ} \mathrm{C}$ to $\sim 1.38 \mathrm{MPa} \mathrm{m}^{1 / 2}$ at $1200{ }^{\circ} \mathrm{C}$, which should be mainly a consequence of the higher crystalline degree of the SiC with more contents of $\beta$-SiC at higher fabrication temperatures.

The fracture toughness of the $\mathrm{Si}_{3} \mathrm{~N}_{4}$ fiber was measured by the micropillar splitting method due to the fibers with dimensions generally $\leq 12 \mu \mathrm{m}$. The detailed testing principles has been reported in our previous study. The acquired experimental load-displacement curves of the fibers were shown in Fig. 9(a). It was obviously observed that the curves displayed typical traces of elastic deformation until brittle failure of the micropillar when the critical load $P_{\mathrm{c}}$ was reached. A typically asfabricated micropillar out of the $\mathrm{Si}_{3} \mathrm{~N}_{4}$ fiber in the crosssection of the composite before and after tests was shown in Fig. 9(b and c). The diameter and height of the micropillars were both $3 \mu \mathrm{m}$. The fracture toughness of the fibers at different
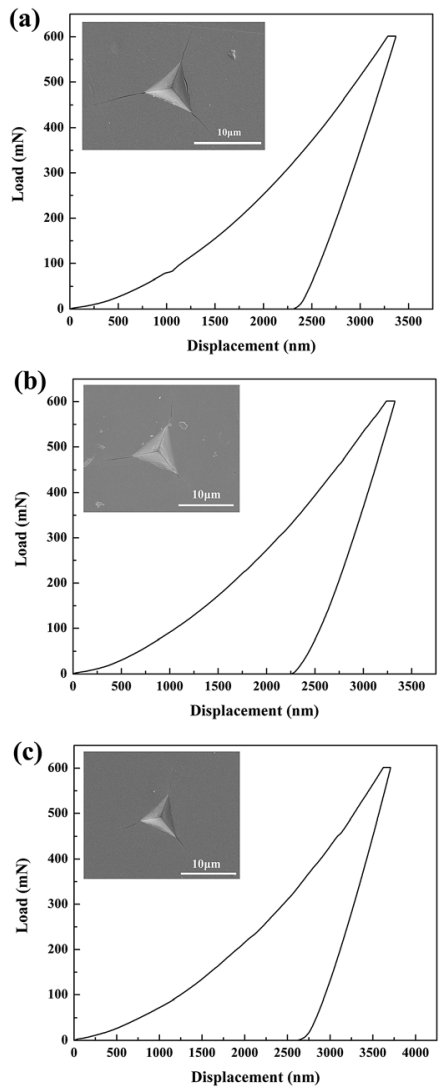

Fig. 8 Representative load-displacement loading and unloading curves for the $\mathrm{SiC}$ matrix inside the composites under a maximum indenting load of $600 \mathrm{mN}$ : (a) $800^{\circ} \mathrm{C}$; (b) $1000^{\circ} \mathrm{C}$; (c) $1200^{\circ} \mathrm{C}$.

Table 2 Fracture toughness of the $\mathrm{SiC}$ matrix by indentation method

\begin{tabular}{lcl}
\hline$T\left({ }^{\circ} \mathrm{C}\right)$ & Crack length $(\mu \mathrm{m})$ & Fracture toughness $\left(\mathrm{MPa} \mathrm{m}^{1 / 2}\right)$ \\
\hline 800 & 11.68 & $1.03 \pm 0.04$ \\
1000 & 8.58 & $1.21 \pm 0.06$ \\
1200 & 7.81 & $1.38 \pm 0.07$
\end{tabular}

fabrication temperatures was estimated from eqn (2) by ref 26 and 27:

$$
K_{\mathrm{IC}}=\gamma \frac{P_{\mathrm{C}}}{R^{2 / 3}}
$$

Here, $R$ is the micropillar radius; $\gamma$ depends on the micropillar size, the material properties and the tip geometry, and has been determined as 0.35 based on our previous work. The fracture toughness of the fibers from $800{ }^{\circ} \mathrm{C}$ to $1200{ }^{\circ} \mathrm{C}$ was close to 2.0 MPa $\mathrm{m}^{1 / 2}$ as listed in Table 3. This is expected due to the high fabrication temperature of these $\mathrm{Si}_{3} \mathrm{~N}_{4}$ fibers $\left(>1300{ }^{\circ} \mathrm{C}\right)$ that the microstructure is almost independent of the composite fabrication temperatures in the temperature range of 800$1200{ }^{\circ} \mathrm{C}$.

\subsection{Interfacial shear strength of the fiber/matrix interface}

The shear property of the fiber/matrix interface in the $\mathrm{Si}_{3} \mathrm{~N}_{4 \mathrm{f}} / \mathrm{SiC}$ composites with and without $\mathrm{BN}$ interphase was quantified by 


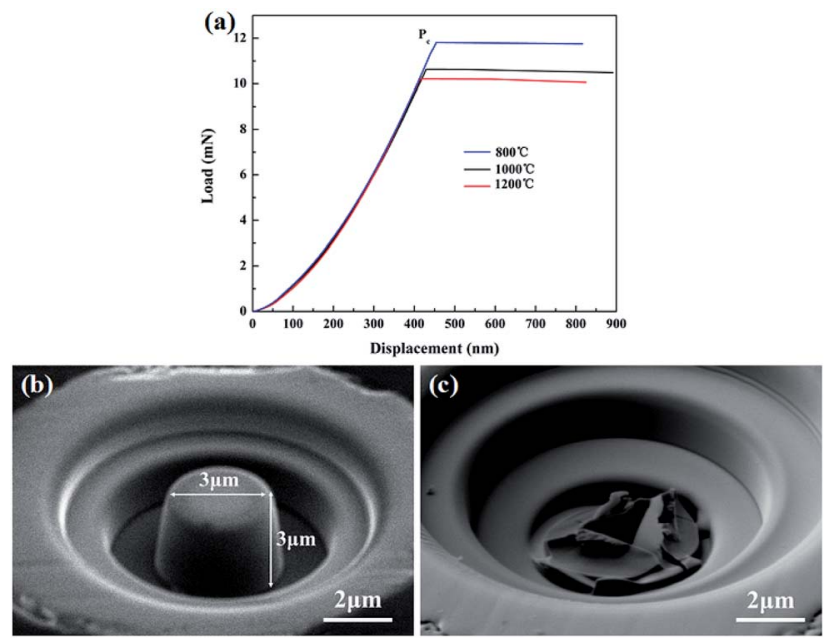

Fig. 9 (a) Representative load-displacement curves for $\mathrm{Si}_{3} \mathrm{~N}_{4}$ fiber micropillars inside the composites; (b) the micropillar morphology before indenting; (c) the micropillar morphology after indenting.

Table 3 Fracture toughness of the $\mathrm{Si}_{3} \mathrm{~N}_{4}$ fiber by micropillar splitting method

\begin{tabular}{lllll}
\hline$T\left({ }^{\circ} \mathrm{C}\right)$ & $R(\mu \mathrm{m})$ & $P_{\mathrm{c}}(\mathrm{mN})$ & $\gamma$ & $\begin{array}{l}\text { Fracture toughness } \\
\left(\mathrm{MPa} \mathrm{m}^{1 / 2}\right)\end{array}$ \\
\hline 800 & 1.5 & 11.83 & 0.35 & $2.08 \pm 0.06$ \\
1000 & & 10.46 & & $2.01 \pm 0.07$ \\
1200 & & 10.28 & & $1.99 \pm 0.05$
\end{tabular}

fiber push-in test. The typical push-in test involves pushing the vertical aligned $\mathrm{Si}_{3} \mathrm{~N}_{4}$ fibers with a flat diamond punch until the interface failure, as shown in Fig. 10(b and c). Based on the obtained push-in load-displacement curves in Fig. 10(a), the interfacial shear strength, $\tau$, can be calculated by eqn (3):
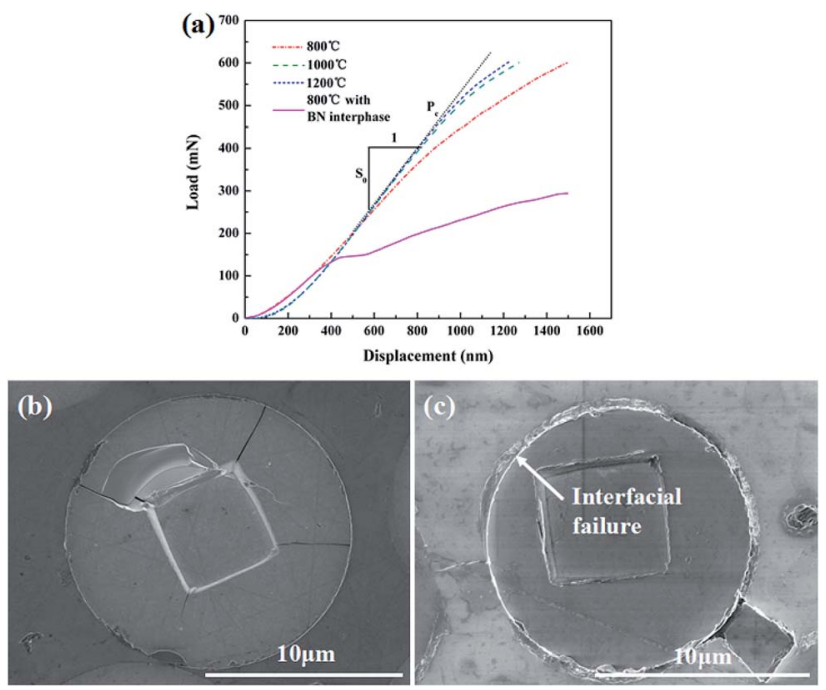

Fig. 10 (a) Fiber push-in tests for the $\mathrm{Si}_{3} \mathrm{~N}_{4 f} / \mathrm{SiC}$ composites with and without BN interphase; fiber morphology after push-in tests: (b) without interphase; (c) with interphase.

$$
\tau_{\mathrm{c}}^{\mathrm{SL}}=\frac{S_{0} P_{\mathrm{c}}}{2 \pi^{2} r^{3} E_{\mathrm{f}}}
$$

Here, $S_{0}$ is the stiffness of the initial linear regime and $P_{\mathrm{C}}$ the critical load leading to the interfacial cracking. $E_{\mathrm{f}}$ is the Young's modulus of $\mathrm{Si}_{3} \mathrm{~N}_{4}$ fiber based on Section 3.2. $R$ is the radius of the fiber, $6.5 \mu \mathrm{m}$. Inputting the corresponding values yielded the interfacial shear strength as listed in Fig. 11. The interfacial shear strength of the $\mathrm{Si}_{3} \mathrm{~N}_{4 \mathrm{f}} / \mathrm{SiC}-800{ }^{\circ} \mathrm{C}$ with interphase $(\sim 140$ $\mathrm{MPa}$ ) was significantly lower than the $\mathrm{Si}_{3} \mathrm{~N}_{4} / \mathrm{SiC}$ composites ( $\sim 420 \mathrm{MPa}$ ), which indicated the BN interphase could tailor the interface bondings.

\subsection{Macro-mechanical property of the $\mathrm{Si}_{3} \mathrm{~N}_{4 \mathrm{f}} / \mathrm{SiC}$ composites}

The macro-mechanical properties of the $\mathrm{Si}_{3} \mathrm{~N}_{4} / \mathrm{SiC}$ composite with and without $\mathrm{BN}$ interphase that are mainly dominated by the measured micro-mechanical properties of the $\mathrm{Si}_{3} \mathrm{~N}_{4}$ fiber, the SiC matrix and the fiber/matrix interface were quantified here by the macro three-point bend tests. The typical stressdisplacement curves of the composites were showed in Fig. 12. The curve of the $\mathrm{Si}_{3} \mathrm{~N}_{4 \mathrm{f}} / \mathrm{SiC}$ composites without BN interphase displayed brittle fracture response after the linear elastic part due to a consequence of the strong fiber/matrix interface that would impede the toughening mechanisms like crack deflection, fiber pull-out, etc. And the curve of the $\mathrm{Si}_{3} \mathrm{~N}_{4 \mathrm{f}} / \mathrm{SiC}-800{ }^{\circ} \mathrm{C}$ composite with BN interphase displayed significantly toughness fracture response. Meanwhile, the flexural strength was increased from $\sim 140 \mathrm{MPa}$ to $\sim 250 \mathrm{MPa}$. The flat fracture surface as shown in Fig. 13(a and b) evidenced the brittle nature of the $\mathrm{Si}_{3} \mathrm{~N}_{4 \mathrm{f}} / \mathrm{SiC}$ composites without introducing interphase. Fig. 13(c and d) showed introducing BN interphase could lead to toughness responses, like interface debonding and fiber pullout, etc.

The difference in the macro-mechanical properties of the $\mathrm{Si}_{3} \mathrm{~N}_{4 \mathrm{f}} / \mathrm{SiC}$ composite and $\mathrm{Si}_{3} \mathrm{~N}_{4 \mathrm{f}} / \mathrm{BN} / \mathrm{SiC}$ composite can be attributed to the interfacial property or the mechanical mismatch of the fiber, interface and matrix, which has been well explained by the well-known He-Hutchinson model. ${ }^{38}$ This model describes the crack penetration/deflection behaviors at the interface of composites. Based on the model, the matrix

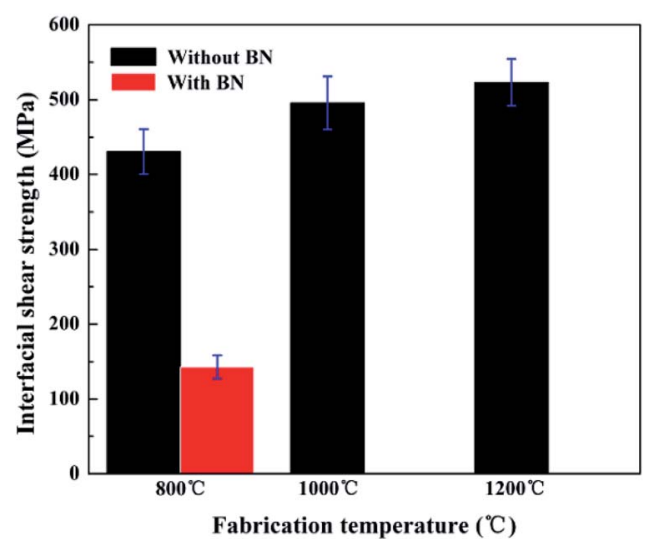

Fig. 11 Interfacial shear strength of the $\mathrm{Si}_{3} \mathrm{~N}_{4 f} / \mathrm{SiC}$ composites with and without BN interphase. 


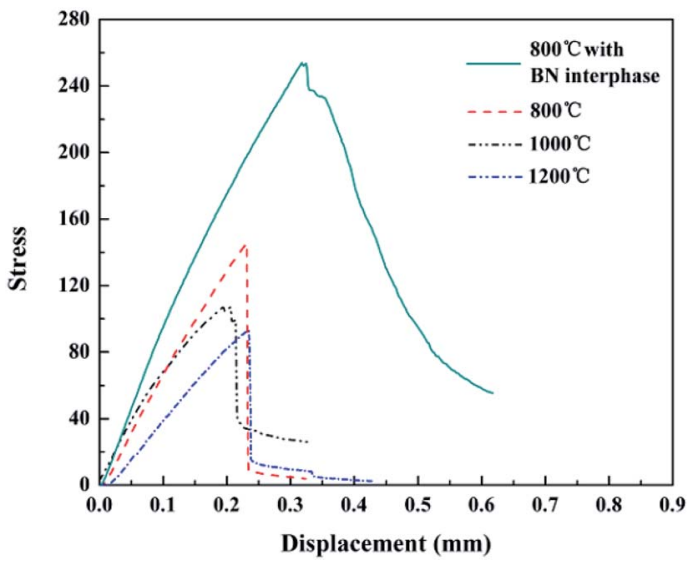

Fig. 12 Representative stress-displacement curves of the $\mathrm{Si}_{3} \mathrm{~N}_{4 f} / \mathrm{SiC}$ composites with and without BN interphase.

crack deflection can occur at the fiber/matrix interface when the composites satisfy the following conditions, and a crack penetration behavior the other way around:

$$
\frac{\Gamma_{\mathrm{i}}}{\Gamma_{\mathrm{f}}}<\frac{G_{\mathrm{d}}}{G_{\mathrm{p}}}
$$

where $\Gamma$ is the toughness and the subscripts f refers to the fiber and $\mathrm{m}$ the matrix in the $\mathrm{Si}_{3} \mathrm{~N}_{4 \mathrm{f}} / \mathrm{SiC}$ composite or the $\mathrm{BN}$ interphase in the $\mathrm{Si}_{3} \mathrm{~N}_{4 \mathrm{f}} / \mathrm{BN} / \mathrm{SiC}$ composite. $G$ is the energy release rate. The subscripts $\mathrm{d}$ and $\mathrm{p}$ refer to the matrix crack deflection and penetration, respectively. The ratio of $G_{\mathrm{d}}$ and $G_{\mathrm{p}}$ can be expressed as the following equations:

$$
\begin{gathered}
\frac{G_{\mathrm{d}}}{G_{\mathrm{p}}}=\frac{1}{4(1-\alpha)^{0.9}} \\
\alpha=\frac{E_{\mathrm{f}}^{*}-E_{\mathrm{m}}^{*}}{E_{\mathrm{f}}^{*}+E_{\mathrm{m}}^{*}} \\
E_{\mathrm{x}}^{*}=\frac{E_{\mathrm{x}}}{1-\nu^{2}}
\end{gathered}
$$
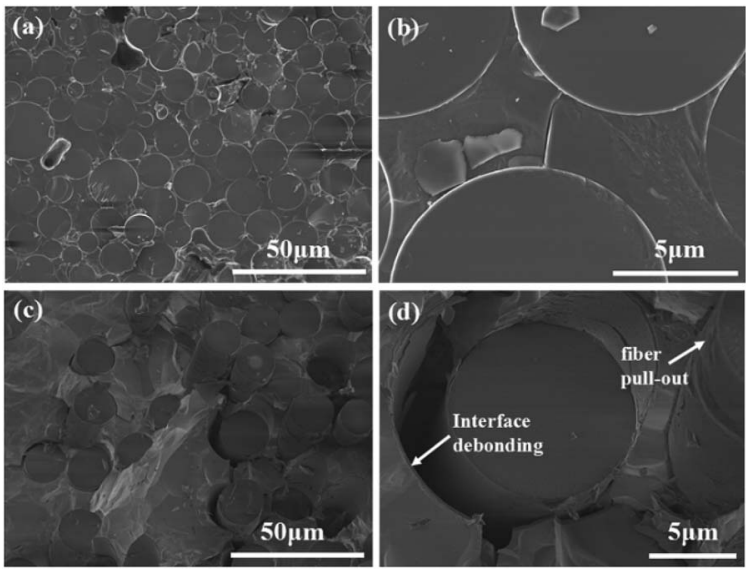

Fig. 13 Fracture surface of $(\mathrm{a}$ and $\mathrm{b})$ the $\mathrm{Si}_{3} \mathrm{~N}_{4 f} / \mathrm{SiC}-800^{\circ} \mathrm{C}$ composite and ( $\mathrm{C}$ and d) $\mathrm{Si}_{3} \mathrm{~N}_{4 \mathrm{f}} / \mathrm{BN} / \mathrm{SiC}-800^{\circ} \mathrm{C}$ composite after three-point bend tests.

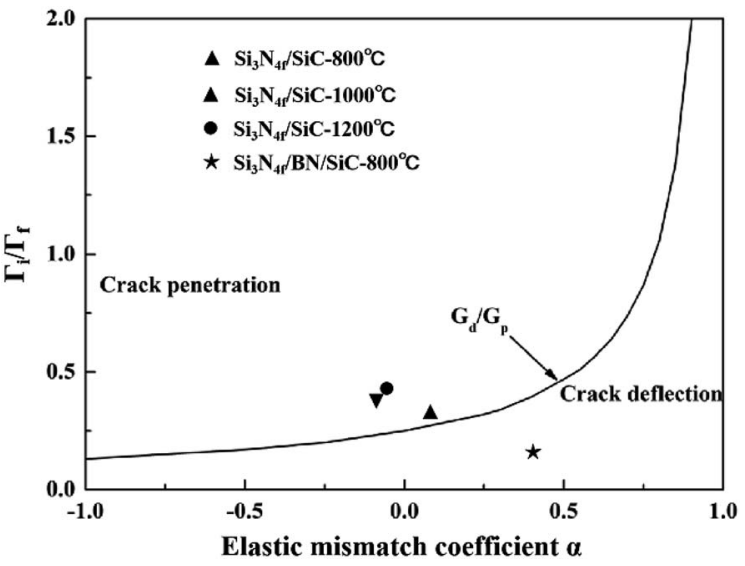

Fig. 14 Crack deflection mode of the $\mathrm{Si}_{3} \mathrm{~N}_{4 f} / \mathrm{SiC}$ composites with and without $\mathrm{BN}$ interphase based on $\mathrm{H}-\mathrm{H}$ model.

here $\alpha$ is elastic mismatch coefficient, $E_{\mathrm{x}}^{*}$ is the plane-strain elastic modulus, $E_{\mathrm{x}}$ and $\nu_{\mathrm{x}}$ correspond to the Young's modulus and the Poisson's ratio of the phase $\mathrm{x}$, respectively.

Note that $\Gamma$ can be calculated by eqn (8):

$$
\Gamma_{\mathrm{x}}=\frac{K_{\mathrm{ICx}}^{2}}{E_{\mathrm{x}}}
$$

here $K_{\mathrm{ICx}}$ correspond to the fracture toughness of the phase x. Note that the SiC fiber toughness $\left(\Gamma_{\mathrm{f}}\right)$ can be quantified using the measured data in this work. The interface toughness $\left(\Gamma_{\mathrm{i}}\right)$ in both the $\mathrm{Si}_{3} \mathrm{~N}_{4 \mathrm{f}} / \mathrm{SiC}$ composite and $\mathrm{Si}_{3} \mathrm{~N}_{4 \mathrm{f}} / \mathrm{BN} / \mathrm{SiC}$ composite, though still missing, was approximated as the $\mathrm{SiC}$ matrix toughness $\left(\Gamma_{\mathrm{m}}\right)$ in the $\mathrm{Si}_{3} \mathrm{~N}_{4 \mathrm{f}} / \mathrm{SiC}$ composite and the BN interphase toughness $\left(\Gamma_{\mathrm{BN}}\right) . \Gamma_{\mathrm{m}}$ was acquired also based on the experimental measurements in this work. The $\Gamma_{\mathrm{BN}}$ was chosen 4 $\mathrm{J} \mathrm{m}^{-1}, 2$ and the Young's modulus $70 \mathrm{GPa}$, based on the literatures. $^{39}$

Fig. 14 shows the He-Hutchinson plot of the different temperature processed $\mathrm{Si}_{3} \mathrm{~N}_{4 \mathrm{f}} / \mathrm{SiC}$ composites with and without $\mathrm{BN}$ interphase studied in this work. The result suggests although the analysis can only be considered as indicative, the He-Hutchinson prediction showed a crack deflection behavior of the $\mathrm{Si}_{3} \mathrm{~N}_{4 \mathrm{f}} / \mathrm{SiC}$ composite with $\mathrm{BN}$ interphase, and a crack penetration behavior of that without $\mathrm{BN}$ interphase in the processing temperature range considered, in accordance to the experimental observations above.

\section{Conclusions}

In this work, the in situ micro-mechanical properties of the novel $\mathrm{Si}_{3} \mathrm{~N}_{4 \mathrm{f}} / \mathrm{SiC}$ composite fabricated though PIP process have been firstly investigated. Meanwhile, the BN interphase was introduced to tailor the fiber/matrix interface in the composites. The conclusions can be summarized as follows:

(1) In the fabrication temperature considered, due to the stable microstructure, the $\mathrm{Si}_{3} \mathrm{~N}_{4}$ fiber showed a stable Young' modulus ( $\sim 165 \mathrm{GPa})$, hardness $(\sim 16 \mathrm{GPa})$ and fracture toughness $\left(\sim 2 \mathrm{MPa} \mathrm{m}^{1 / 2}\right)$, indicating an excellent thermal- 
mechanical property of the $\mathrm{Si}_{3} \mathrm{~N}_{4}$ fiber that was barely degraded after high temperature composite fabrication process;

(2) A more crystallized SiC matrix that is mainly attributed to the higher contents of $\beta$-SiC formations with the temperatures increased from $800{ }^{\circ} \mathrm{C}$ to $1200{ }^{\circ} \mathrm{C}$, which subsequently resulted in enhancements in the Young's modulus, hardness and fracture toughness;

(3) The interfacial microstructure analysis of the $\mathrm{Si}_{3} \mathrm{~N}_{4 \mathrm{f}} / \mathrm{SiC}$ composites showed the interface was reaction-controlled and the fiber bonded with the matrix tightly, as evidenced by the high interfacial shear strength $(>420 \mathrm{MPa})$. After introducing the $\mathrm{BN}$ interphase, the interfacial shear strength can be significantly decreased to $\sim 140 \mathrm{MPa}$ because of preventing the interfacial reactions.

(4) The strong interfacial reactions of the $\mathrm{Si}_{3} \mathrm{~N}_{4 \mathrm{f}} / \mathrm{SiC}$ composites led to the elastic-brittle responses. However, the composites with $\mathrm{BN}$ interphase showed a significantly enhanced fracture resistance, due to the triggering of the toughening mechanisms like interfacial debonding, fiber pullout, etc.

To sum up, the methods utilized in the paper likewise can be extended to the other continuous ceramic fibers reinforced ceramic matrix composites.

\section{Conflicts of interest}

There are no conflicts to declare.

\section{Acknowledgements}

The authors appreciate the Aid Program for Innovative Group of National University of Defense Technology, and the Aid program for Science and Technology Innovative Research Team in Higher Educational Institutions of Hunan Province.

\section{Notes and references}

1 S. Y. Cao, J. Wang and H. Wang, Mater. Sci. Eng. A, 2016, 673, 55-62.

2 H. T. Liu and H. Tian, J. Eur. Ceram. Soc., 2012, 32, 25052512.

3 S. Y. Cao, J. Wang and H. Wang, J. Mater. Sci., 2016, 51, 1-10.

4 Z. M. Li, W. C. Zhou and X. L. Su, J. Alloys Compd., 2011, 509, 973-976.

5 T. H. Xu, Q. S. Ma and Z. H. Chen, Mater. Lett., 2011, 65, 1538-1541.

6 R. Mo, X. W. Yin and F. Ye, J. Eur. Ceram. Soc., 2019, 39, 743754.

7 H. Luo, W. B. Chen and W. Zhou, Ceram. Int., 2017, 43, 12328-12332.

8 H. B. Jin, M. S. Cao and W. Zhou, Mater. Res. Bull., 2010, 45, 247-250.

9 C. R. Zou, C. R. Zhang and Y. Xiao, J. Non-Cryst. Solids, 2012, 358, 3338-3341.

10 Q. Ding, D. W. Ni and Z. Wang, J. Adv. Ceram., 2018, 7, 266275.
11 X. L. Fan, W. Liu and X. G. Lu, J. Mater. Sci. Lett., 2005, 40, 6033-6036.

12 Y. Li and J. C. Gao, Mater. Lett., 2013, 110, 102-104.

13 X. Hu, C. W. Shao and J. Wang, J. Mater. Sci., 2016, 52, 75557566.

14 X. Sun, H. T. Liu and H. F. Cheng, $R S C A d v ., 2017$, 7, 4783347839.

15 K. Yoshida, J. Ceram. Soc. Jpn., 2010, 118, 82-90.

16 R. Naslain, A. Guette and F. Rebillat, J. Mater. Sci., 2004, 39, 7303-7316.

17 D. Frazer, M. D. Abad and D. Krumwiede, Composites, Part A, 2015, 70, 93-101.

18 D. Blaese, D. E. Garcia and P. Guglielmi, J. Eur. Ceram. Soc., 2015, 35, 1593-1598.

19 W. Yan, C. L. Pun and Z. Wu, Composites, Part B, 2011, 42, 2093-2097.

20 T. P. Wang, C. F. Liu and L. Christian, Mater. Sci. Eng. A, 2016, 650, 469-477.

21 Y. M. He, Y. Sun and J. Zhang, J. Eur. Ceram. Soc., 2012, 32, 3379-3388.

22 A. Udayakumar, G. A. Sri and S. Raja, J. Eur. Ceram. Soc., 2011, 31, 1145-1153.

23 L. Zhang, C. Ren and C. Zhou, Appl. Surf. Sci., 2015, 357, 1427-1433.

24 T. Hinoki, J. Nucl. Mater., 1998, 2, 1567-1571.

25 M. Kharrat, A. Chateauminois and L. Carpentier, Composites, Part A, 1997, 28, 39-46.

26 M. Sebastiani, K. E. Johanns and E. G. Herbert, Philos. Mag., 2015, 95, 1928-1944.

27 M. Sebastiani, K. E. Johanns and E. G. Herbert, Curr. Opin. Solid State Mater. Sci., 2015, 19, 324-333.

28 S. Han, L. W. Yang and H. T. Liu, Mater. Des., 2017, 131, 265272.

29 X. K. Ma, X. W. Yin and X. Y. Cao, Ceram. Int., 2016, 42, 36523658.

30 R. R. Naslain, Composites, Part A, 1998, 29, 1145-1155.

31 X. D. Li and B. S. Bharat, Mater. Charact., 2002, 48, 11-36.

32 X. Sun, H. T. Liu and H. F. Cheng, Ceram. Int., 2018, 136, 231-235.

33 P. Colombo, G. Mera and R. Riedel, J. Am. Ceram. Soc., 2010, 93, 1805-1837.

34 H. Liu, H. F. Cheng and J. Wang, Mater. Sci. Eng. A, 2009, 525, 121-127.

35 J. Lipowitz, J. A. Rabe and K. T. Nguyen, Proc. 19th Annu. Conf. Compos. Adv. Ceram. Mater. Struct. Ceram. Eng. Sci. Proc., John Wiley \& Sons, Inc., 1995.

36 M. A. Khakani, M. Chaker and A. Jean, J. Mater. Res., 1994, 9, 96-103.

37 B. R. Lawn, A. G. Evans and D. B. Marshall, J. Am. Ceram. Soc., 1980, 20, 574-581.

38 M. Y. He, A. G. Evans and J. W. Hutchinson, Int. J. Solids Struct., 1994, 31, 3443-3455.

39 D. Cornu and S. Bernard, J. Eur. Ceram. Soc., 2005, 25, 111121. 